\title{
Assessment of Aflatoxin and Fumonisin Contamination of Maize in Western Kenya
}

\author{
S. K. Mutiga, V. Hoffmann, J. W. Harvey, M. G. Milgroom, and R. J. Nelson
}

First, fourth, and fifth authors: School of Integrative Plant Science, Section of Plant Pathology and Plant-Microbe Biology, Cornell University, Ithaca, NY 14853; second author: International Food Policy Research Institute, 2033 K Street NW, Washington DC 20006; and third author: Biosciences Eastern and Central Africa-International Livestock Research Institute (BecA-ILRI) Hub, P.O. Box 30709, Nairobi 00100, Kenya. Accepted for publication 14 April 2015.

\begin{abstract}
Mutiga, S. K., Hoffmann, V., Harvey, J. W., Milgroom, M. G., and Nelson, R. J. 2015. Assessment of aflatoxin and fumonisin contamination of maize in western Kenya. Phytopathology 105:1250-1261.

We conducted a survey of aflatoxin and fumonisin in maize in western Kenya. In a regional survey of aflatoxin conducted in 2009 across three agroecological zones within three administrative regions, milled maize samples were collected from 985 patrons of 26 hammer mills. Aflatoxin contamination was detected in $49 \%$ of samples and was above the regulatory (10 ppb) in $15 \%$ of the samples overall; $65 \%$ of samples from a drought-prone area were over the limit. In a detailed survey in Bungoma County, we investigated aflatoxin and fumonisin

storage sheds and milled samples from patrons of local mills. Mean aflatoxin contamination was identical for storage sheds and mills at $2.3 \mathrm{ppb}$. In all, $41 \%$ of the samples from mills had detectable aflatoxin, with $4 \%$ over the regulatory limit, whereas $87 \%$ had detectable fumonisin, with $50 \%$ over the regulatory limit (1 ppm). Mean contamination levels did not change during storage. Maize varieties differed in fumonisin contamination, with the most popular varieties vulnerable to both mycotoxins and weevils, which are potential factors in exacerbating mycotoxin contamination. Mycotoxin surveillance is important not just in areas known previously for aflatoxin contamination and acute poisoning but also is needed in all maize-producing regions.
\end{abstract} contamination in four popular maize varieties at harvest and after 2 and 4 months of storage. We collected whole-grain samples from farmers'
Additional keywords: food safety, intercrops, maize value chain, tropical.
There is increasing concern about mycotoxin contamination in tropical food systems. Significant attention has been focused on regions where outbreaks of fatal mycotoxicosis tend to occur. For example, the recurrent outbreaks of aflatoxin contamination of maize and fatal aflatoxicosis in eastern Kenya have received considerable attention (Daniel et al. 2011; Kang'ethe 2011; Nyikal et al. 2004). However, little information is available on the occurrence and the extent of aflatoxin or other mycotoxin contamination in most areas of Africa, including the western region of Kenya, where most of the country's maize is produced.

Maize is grown in Kenya under agroclimatic conditions that favor fungal colonization and mycotoxin accumulation (Kedera et al. 1999; Okoth et al. 2012). Approximately $75 \%$ of Kenyan maize is produced by resource-poor farmers under conditions that could predispose the crop to mycotoxin contamination. The maize value chain, which includes the sequential processes from production to consumption of maize, lacks mechanisms for ensuring food safety (Kang'ethe 2011). The factors that influence the accumulation of mycotoxins along the African maize value chains are poorly understood. Mycotoxin surveillance at key points, such as storage and milling, is important to facilitate management strategies that would reduce health risks.

The best-known mycotoxins in maize include aflatoxin, produced by Aspergillus flavus and A. parasiticus, and fumonisin, produced by Fusarium verticillioides (Burger et al. 2010; Williams et al. 2005). Acute exposure to high levels of aflatoxin can be fatal, while chronic exposure has been associated with growth stunting in children, immunosuppression, and liver cancer (Kimanya

Corresponding author: R. J. Nelson: E-mail address: rjn7@ cornell.edu

http://dx.doi.org/10.1094/PHYTO-10-14-0269-R

(C) 2015 The American Phytopathological Society et al. 2010; Williams et al. 2004). Consumption of fumonisincontaminated maize has been associated with growth stunting and esophageal cancer (Kimanya et al. 2010). Coexposure to the two mycotoxins has been shown to increase the frequency of liver cancer in animal studies (Carlson et al. 2001). The World Food Program (WFP) set the regulatory limits for aflatoxin at $10 \mathrm{ppb}$ $(10 \mu \mathrm{g} / \mathrm{kg})$ and for fumonisin at $1 \mathrm{ppm}(1 \mathrm{mg} / \mathrm{kg})$ (van Egmond et al. 2007). Because of the high cost of mycotoxin analysis, few developing countries effectively monitor mycotoxin levels in their food systems. Like many countries, Kenya has adopted the WFP regulatory limits for mycotoxins; however, it lacks the capacity for systematic mycotoxin monitoring and the government has not fully implemented the regulations (Hell and Mutegi 2011; Whitaker 2011; Whitaker et al. 2007).

Maize is the main staple food in Kenya, contributing $65 \%$ of staple food calories and $36 \%$ of the total caloric intake (Ahmed 2011). Small-scale farmers store maize under varying and often suboptimal conditions for up to 4 months before home use or sale (Hell and Mutegi 2011; Jaetzold et al. 2006). Families often consume some of the maize they grow, sell some to raise cash, and buy locally marketed maize as need arises (Ahmed 2011). An estimated $60 \%$ of maize is processed by consumers at neighborhood hammer mills (Kang'ethe 2011). Clients typically process 2 to $10 \mathrm{~kg}$ of maize at a time at these local mills, known locally as posho mills, for consumption over the subsequent few days.

As a basis for developing effective mycotoxin mitigation strategies, there is need to assess the extent of contamination and the factors associated with it. The final level of mycotoxin contamination of a maize sample depends on the extent of fungal colonization and toxin production at each stage along the value chain (Hell and Mutegi 2011). Because local mills are the final processing points for the majority of Kenyan maize, they are strategic sites for surveillance of mycotoxin contamination (Mutiga 
et al. 2014). In the current study, we investigated the extent of mycotoxin contamination in western Kenya at harvest, in storage, and at the local mills.

Western Kenya (Nyanza, Rift Valley and Western regions; hereafter referred to as W. Kenya, to distinguish it from the former administrative province) produces over $75 \%$ of the maize consumed in Kenya. Consumers in most parts of the country depend on the maize that is produced in W. Kenya (Reynolds 2009). Mycotoxicosis outbreaks have not been reported in this region, although the lack of fatalities and mycotoxin surveillance could mean that problems have gone unnoticed. The few mycotoxin-related studies conducted in the region have shown that fumonisin contamination could be more prevalent than aflatoxin contamination but the studies were limited in sample size and geographical scope. A previous survey in W. Kenya reported fumonisin in $47 \%$ of samples of maize samples $(n=197)$ from storage sheds, with $5 \%$ above the regulatory limit (Kedera et al. 1999). A survey of four maize varieties in 24 farms in the former Western Province reported aflatoxin up to $20 \mathrm{ppb}$ in three samples (Alakonya et al. 2009). A high prevalence of aflatoxin contamination in groundnut (Arachis hypogaea L.; also known as peanut) was recently reported in W. Kenya (Mutegi et al. 2009) but groundnut production and consumption are not as widespread as maize. Analysis of human blood serum revealed lower levels of exposure to aflatoxin in W. Kenya than elsewhere in the country (Yard et al. 2013).

Factors that increase the vulnerability of maize to mycotoxin contamination include preharvest biotic and abiotic stress, genetic factors of maize and pathogens that favor colonization and toxigenesis, and improper postharvest management (Hell et al. 2008; Wiatrak et al. 2005). Drought, insect pressure, and soil degradation or infertility are among the environmental factors contributing to preharvest stress (Bruns 2003). Toxigenicity of the fungal populations is another variable that is poorly understood; Aspergillus flavus genotypes of varying toxin-production potential have been reported in Kenya (Okoth et al. 2012; Probst et al. 2012). The A. flavus population in eastern Kenya, where outbreaks of aflatoxicosis are most frequently reported, is particularly aflatoxigenic (Probst et al. 2012).

Maize genotypes differ in susceptibility to mycotoxin accumulation, and breeding for reduced susceptibility is an important mycotoxin management strategy (Hell and Mutegi 2011; Williams 2006). Cultivated maize consists of hybrid and open-pollinated varieties (Jaetzold and Schmidt 1982). Complete resistance of maize to aflatoxin and fumonisin does not exist and the two complex traits are controlled by multiple genes (Fountain et al. 2014; Williams 2006). Mycotoxin accumulation is influenced by maize and fungal genotypes $\left(\mathrm{G}_{\mathrm{M}}\right.$ and $\mathrm{G}_{\mathrm{F}}$, respectively), environment $(\mathrm{E})$, farm management factors $(\mathrm{M})$, and the interactions among these factors $\left(\mathrm{G}_{\mathrm{M}} \times \mathrm{G}_{\mathrm{F}} \times \mathrm{M} \times \mathrm{E}\right)$ (Bolduan et al. 2009; Fountain et al. 2014). Grain characteristics such as kernel texture (endosperm type) are among the genetically determined traits of maize that may influence susceptibility to pre- and postharvest mycotoxin accumulation (Betran et al. 2006).

The objectives of this study were to assess the prevalence of aflatoxin contamination in maize in a major maize-growing area where an outbreak has not been recognized, investigate the factors associated with aflatoxin contamination in maize, and assess aflatoxin and fumonisin contamination in selected maize varieties at different points on the maize value chain.

\section{MATERIALS AND METHODS}

Study sites. Surveys were conducted in western Kenya in 2009 and 2010 to assess mycotoxin contamination in maize. The regional survey involved sampling flour at local mills in the Nyanza, Western, and Rift Valley regions of W. Kenya between May and July 2009 (Table 1; Fig. 1). Sites were identified to sample from local mills in three maize-producing agroecological zones (AEZs) (humid, subhumid, and semihumid) using a geographic information system overlay of AEZs and administrative boundaries. Six major towns that serve as either county or subcounty headquarters within the three regions were selected as sampling hubs (Fig. 1). Villages that represent different AEZs and were located within a $20-\mathrm{km}$ radius from the sampling hub were selected as potential sampling sites. After stratifying by AEZ, 26 villages were randomly selected from this sampling frame. One mill within each selected village was randomly selected for sampling, conditional on the consent of its owner (Table 1). Samples collected from all mills within the same AEZ in the same county were considered to represent the same geoclimatic location (Tables 1 and 2).

The more detailed survey involved sampling of whole-grain maize from farmers' storage sheds and flour from local mills within seven villages located in a humid AEZ of Bungoma County, Western region, from August 2009 to March 2010; this is hereafter termed the "Bungoma survey". Sampling for the Bungoma survey was conducted at different stages of the maize value chain: at harvest, after 2 and then 4 months of storage, and finally at local mills. Mycotoxins detected in samples from the mills were an indicator of human exposure at the time this study was conducted.

The mills included in the Bungoma survey were different from those in the regional survey. The Bungoma sites were identified with guidance from authorities in the Kenyan Ministry of

TABLE 1. Geoclimatic locations, rainfall patterns, and sites (mills) where maize flour samples were collected in a regional survey of western Kenya in 2009a

\begin{tabular}{|c|c|c|c|c|c|c|c|c|c|c|}
\hline $\begin{array}{l}\text { Region } \\
\text { (formerly } \\
\text { province) }\end{array}$ & County & $\begin{array}{l}\text { Subcounty } \\
\text { (formerly } \\
\text { district) }\end{array}$ & $\begin{array}{l}\text { Sampling } \\
\text { hub }\end{array}$ & AEZ & $\begin{array}{l}\text { Altitude } \\
(\text { masl })^{b}\end{array}$ & $\begin{array}{l}\text { Rainfall } \\
\text { pattern }^{\mathrm{c}}\end{array}$ & $\begin{array}{l}\text { Maize-growing } \\
\text { season (days) }\end{array}$ & $\begin{array}{c}\text { Expected } \\
\text { rainfall } \\
\text { range }(\mathrm{mm})\end{array}$ & $\begin{array}{l}\text { Rainfall } \\
(\mathrm{mm}) \text { in } \\
2008 / 2009^{d}\end{array}$ & $\begin{array}{c}\text { Number } \\
\text { of mills } \\
(n)^{\mathrm{e}}\end{array}$ \\
\hline Nyanza & Homa Bay & Rachuonyo & Kosele & Semihumid & $1,140-1,350$ & Bimodal & $135-154$ & $350-500$ & 578 & 2 \\
\hline Nyanza & Homa Bay & Rachuonyo & Kosele & Subhumid & $1,300-1,500$ & Bimodal & $135-154$ & $700-950$ & 624 & 1 \\
\hline Nyanza & Homa Bay & Homa Bay & Homa Bay & Humid & $1,300-1,500$ & Bimodal & $135-154$ & $700-950$ & 617 & 2 \\
\hline Nyanza & Homa Bay & Homa Bay & Homa Bay & Subhumid & $1,140-1,450$ & Bimodal & $135-154$ & $500-800$ & 679 & 1 \\
\hline Nyanza & Kisii & Kisii & Kisii & Humid & $1,800-2,165$ & Bimodal & $135-154$ & $400-700$ & 462 & 3 \\
\hline Western & Bungoma & Bungoma & Bungoma & Humid & $1,350-1,500$ & Bimodal & $195-214$ & $700-800$ & 879 & 6 \\
\hline Western & Bungoma & Bungoma & Bungoma & Subhumid & $1,350-1,550$ & Bimodal & $195-214$ & $650-700$ & 857 & 2 \\
\hline Rift Valley & Trans-Nzoia & Trans-Nzoia & Kitale & Semihumid & $1,650-1,850$ & Unimodal & $195-214$ & $950-1,020$ & 852 & 2 \\
\hline Rift Valley & Trans-Nzoia & Trans-Nzoia & Kitale & Subhumid & $1,700-1,950$ & Unimodal & $195-214$ & $1,050-1,250$ & 840 & 3 \\
\hline Rift Valley & Uasin Gishu & Uasin Gishu & Eldoret & Semihumid & $1,900-2,400$ & Unimodal & $195-214$ & $900-1,300$ & 827 & 2 \\
\hline Rift Valley & Uasin Gishu & Uasin Gishu & Eldoret & Subhumid & $2,300-2,400$ & Unimodal & $195-214$ & $1,150-1,220$ & 969 & 2 \\
\hline Total & $\ldots$ & $\ldots$ & $\ldots$ & $\ldots$ & $\ldots$ & $\ldots$ & $\ldots$ & $\ldots$ & $\ldots$ & 26 \\
\hline
\end{tabular}

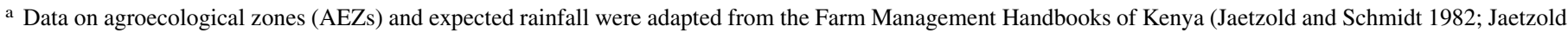
et al. 2006).

b Meters above sea level.

c Two crop seasons per year (bimodal) and one crop season per year (unimodal).

d Rainfall data for the year 2008/2009 was retrieved at World Climate repository (http://www.worldclim.org).

e Number of sampling sites within an AEZ in each subcounty. 
Agriculture to fulfill the following criteria: relative climatic uniformity, agroclimatic conditions representative of the major maize-growing area of W. Kenya, maize as the predominant crop, small-scale maize production, cultivation of multiple maize varieties that represented the diversity of maize in the region, maize harvest coinciding with the start of our survey, and few or no nongovernmental maize development agencies operating in the area (such organizations would be expected to influence farmers' maize production activities, and instructions from such organizations might have either interfered with our survey or influenced its results).

The seven villages were identified as sampling sites based on preharvest assessment visits (reconnaissance) to 13 villages within a $10-\mathrm{km}$ radius from the Bungoma town center. For each of the 13 villages, 30 farmers were interviewed about the maize varieties they grew, time to maturity of each variety and the expected harvest date.

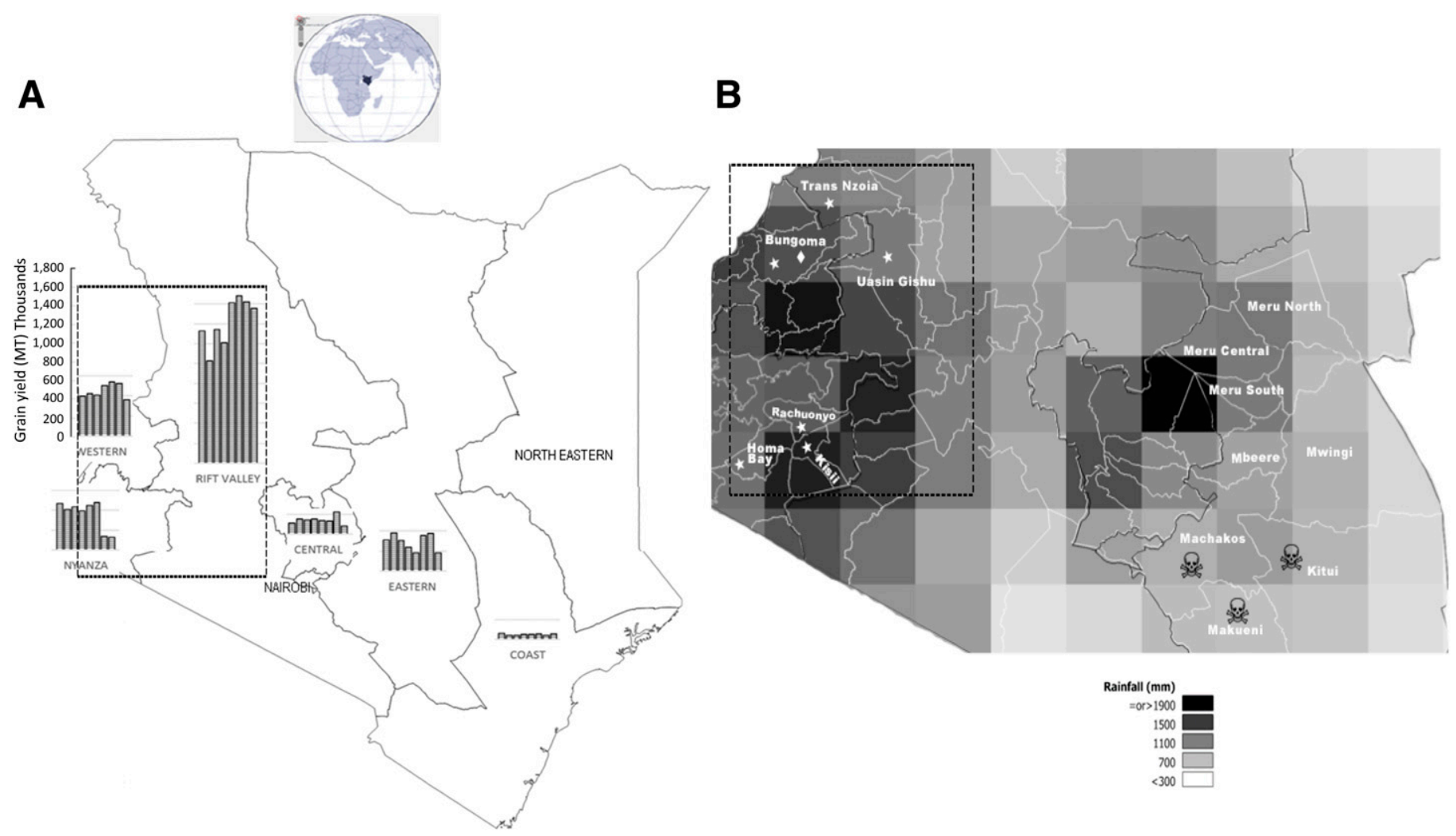

Fig. 1. Map of Kenya showing A, maize grain yield (vertical bars in metric tons [MT]) (http://fsg.afre.msu.edu/gis/) from 2001 to 2008 for six administrative regions (formerly provinces) and B, counties in western Kenya, where studies were conducted in 2009 to 2010. The approximate location of Kenya's main maize production area is shown by the dashed rectangles in both maps. Counties (or subcounty in the case of Rachuonyo) where sampling was conducted as part of a regional survey are indicated by one white star, while a white star and white diamond at Bungoma indicates the two studies (regional and detailed surveys) that were conducted. Fatal aflatoxicosis has previously been reported in eastern Kenya in regions shown with hazard symbols. Grayscale indicates long-term average annual rainfall (mm) (http://harvestchoice.org/products/data/263).

TABLE 2. Regional survey of aflatoxin contamination in maize collected from local mills across geoclimatic locations in western Kenya ${ }^{a}$

\begin{tabular}{|c|c|c|c|c|c|c|c|c|c|c|c|}
\hline \multirow{2}{*}{$\begin{array}{l}\text { Region } \\
\text { (formerly } \\
\text { province) }\end{array}$} & \multirow[b]{2}{*}{ County } & \multirow{2}{*}{$\begin{array}{l}\text { Subcounty } \\
\text { (formerly } \\
\text { district) }\end{array}$} & \multirow{2}{*}{$\begin{array}{l}\text { Agroecological } \\
\text { zone (AEZ) }\end{array}$} & \multirow{2}{*}{$\begin{array}{c}\text { Sample } \\
\text { size }\left(n_{1}\right)\end{array}$} & \multirow{2}{*}{$\begin{array}{c}\text { Complete } \\
\text { questionnaires } \\
\left(n_{2}\right)\end{array}$} & \multirow{2}{*}{$\begin{array}{l}\text { Home-grown } \\
\text { maize }(\%)^{\mathrm{c}}\end{array}$} & \multirow{2}{*}{$\begin{array}{l}\text { Mean farm } \\
\text { size }(\text { ha })^{\mathrm{d}}\end{array}$} & \multirow{2}{*}{$\begin{array}{c}\text { Top } \\
\text { quartile } \\
\text { range } \\
\text { (ppb) }\end{array}$} & \multicolumn{3}{|c|}{$\begin{array}{c}\text { Distribution } \\
\text { of samples }(\%) \\
\text { with aflatoxin } \\
\text { contamination }^{\text {b }}\end{array}$} \\
\hline & & & & & & & & & $<1 \mathrm{ppb}$ & $>1 \mathrm{ppb}$ & $>10 \mathrm{ppb}$ \\
\hline Nyanza & Homa Bay & Rachuonyo & Semihumid & 71 & 44 & 45 & 0.7 & $16-710$ & 7 & 93 & 65 \\
\hline Nyanza & Homa Bay & Rachuonyo & Subhumid & 33 & 19 & 59 & 0.8 & $2-51$ & 58 & 42 & 9 \\
\hline Nyanza & Homa Bay & Homa Bay & Subhumid & 44 & 10 & 57 & 1 & $15-19$ & 34 & 66 & 32 \\
\hline Nyanza & Homa Bay & Homa Bay & Humid & 69 & 20 & 56 & 0.3 & $13-51$ & 29 & 71 & 29 \\
\hline Nyanza & Kisii & Kisii & Humid & 125 & 48 & 40 & 0.8 & 2-18 & 55 & 45 & 8 \\
\hline Western & Bungoma & Bungoma & Subhumid & 83 & 71 & 43 & 1.5 & $2-24$ & 55 & 45 & 2 \\
\hline Western & Bungoma & Bungoma & Humid & 226 & 172 & 27 & 0.9 & $2-52$ & 57 & 43 & 3 \\
\hline Rift Valley & Trans-Nzoia & Trans-Nzoia & Semihumid & 65 & 52 & 63 & 1.3 & $1-200$ & 51 & 49 & 7 \\
\hline Rift Valley & Trans-Nzoia & Trans-Nzoia & Subhumid & 127 & 99 & 29 & 1.3 & $1-32$ & 62 & 38 & 3 \\
\hline Rift Valley & Uasin Gishu & Uasin Gishu & Semihumid & 75 & 53 & 54 & 0.9 & $0-79$ & 80 & 20 & 5 \\
\hline Rift Valley & Uasin Gishu & Uasin Gishu & Subhumid & 67 & 58 & 38 & 0.8 & $1-31$ & 69 & 31 & 4 \\
\hline Total & $\ldots$ & ... & $\ldots$ & 985 & 646 & 32 & $\ldots$ & $2-710$ & 51 & 49 & 15 \\
\hline
\end{tabular}

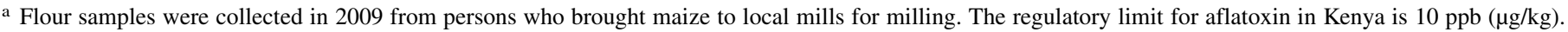

b Lower limit of detection of aflatoxin is $1 \mathrm{ppb}$; percentages under " $>1 \mathrm{ppb}$ " include samples with aflatoxin $>10$ ppb, above the regulatory limit.

c Based on number of completed questionnaires $\left(n_{2}\right)$.

d Mean area of land cultivated with maize by farmers that were interviewed in each geoclimatic location. 
Further information about the characteristics of each of the varieties was obtained from a Tegemeo Institute working paper (Tegemeo Institute 2010), from brochures of seed traders, and by inspection of kernel traits. To understand whether the varieties differed in their vulnerability to mycotoxin accumulation under farmers' conditions and at key points in the value chain, we sampled and analyzed mycotoxins associated with four popular varieties grown in W. Kenya. We sought a range of maize kernel endosperm types (e.g., flint, semiflint, or dent) in selecting the four varieties, based on prior reports that this kernel trait was associated with mycotoxin contamination (Betran et al. 2006; Clements et al. 2004).

Study design and sampling strategy. For the regional survey of local mills, centrally trained research assistants interviewed and collected samples ( $n=985$ ) of milled maize from individuals who processed maize at the 26 mills. From each mill, 30 to 45 samples were collected over a 3- to 5-day period. For each sample, a questionnaire was administered on how the respondent acquired the maize. For those with home-grown maize, we collected data on pre- and postharvest management of the crop.

For the Bungoma survey, we selected farmer participants $(n=$ 186) who grew at least one of the four popular varieties within the seven villages. Because weevil damage of maize in storage has been correlated previously with mycotoxin accumulation in other tropical regions (Atukwase et al. 2009; Kaaya et al. 2006), we investigated whether weevil incidence was correlated with aflatoxin and fumonisin. A subset of farmers $(n=40)$ was randomly selected to assess whether commonly used deterrents (e.g., commercial synthetic pesticides, botanicals, or ash, hereafter called "preservatives") against grain weevils (Sitophilus zeamais Motsch.) affected mycotoxin accumulation. For each of the home-grown maize varieties, the participants in the grain-preservatives study were provided with a pair of woven polypropylene storage bags, the typical maize storage bags in East Africa (Kaaya and Kyamuhangire 2006), which could hold $10 \mathrm{~kg}$ of maize. Participants were asked to put their treated and nontreated home-grown maize grain in the appropriately labeled bags, and to store the sample bags in their sheds. Interviews were conducted and samples collected at three times: at harvest and at 2 and 4 months after harvest. Interviews at harvest provided information on preharvest management practices, while later interviews provided data on postharvest conditions.

Interviews at harvest and ear rot assessment were conducted within the first 2 days of harvest (prior to maize shelling). Ear rot was visually assessed for each maize variety on randomly selected ears that filled a polypropylene bag of $10-\mathrm{kg}$ grain capacity. Ears were scored based on percentage of rotten kernels, as follows: $1=$ no rot, $2=$ some rot but below $25 \%, 3=26$ to $50 \%, 4=51$ to $75 \%$, and $5=$ greater than $75 \%$. Data were recorded as number of ears per bag in each category, and the average scores were calculated.

Maize was shelled and packaged into $90-\mathrm{kg}$ polypropylene bags; then whole-grain samples were collected from up to three bags that the participants stored and also from the $10-\mathrm{kg}$ bags in the grainpreservative experiment. Maize was sampled using two devices: a double-tube spear for grain stored in $90-\mathrm{kg}$ bags and a closed spear for grain in 10-kg bags (Proctor 1994). The sampling device was inserted at different depths from the mouth of the bag to obtain nine subsamples of approximately $100 \mathrm{~g}$ each. At each grain sampling date, grain moisture and weevil incidence were assessed. Grain moisture was measured using an SC 4A digital sensor (Zhejiang Top Instrument Co., Ltd.) at nine points (three at the top, three in the middle, and three at the bottom) for every three $90-\mathrm{kg}$ polypropylene bags. Weevil incidence was scored on each of the nine subsamples using the following scale: $0=$ no weevils, $1=1$ to $2,2=$ 3 to $5,3=6$ to 10 , and $4=>10$ weevils. After the grain was scored for weevils, the subsamples were pooled and mixed, and a final 100-g whole-grain sample was drawn for mycotoxin analysis.

In addition, we collected 100-g flour samples from individuals who processed maize destined for immediate consumption at a local mill in each of the villages where there was a concurrent storage-shed survey. Research assistants collected the flour samples and survey responses from 30 adults at each mill in a 3-day period during each of the three sampling periods for the storage study. Prior to sampling, the mill customers had processed samples of 2 to $10 \mathrm{~kg}$. Flour was mixed before the subsamples were taken. Individuals were interviewed on maize variety and pre- and postharvest management practices.

Sample handling and mycotoxin analysis. Mycotoxins were analyzed using commercially available enzyme-linked immunosorbent assay (ELISA) kits (Helica Biosystems Inc.), the performance of which had been previously validated (Mutiga et al. 2014). Aflatoxin was extracted from 5-g subsamples of maize flour using $70 \%$ methanol and was analyzed following the manufacturer's protocol. Whole-grain samples were ground in the laboratory in a Romer mill (Romer Labs, Inc.). The solid-phase direct competitive aflatoxin ELISA kit (catalog number 941BAFL01-96; Helica Biosystems Inc.) consisted of a 96-well microplate coated with an antibody that had been optimized to cross-react with the four aflatoxin types at the following rates: $\mathrm{B} 1=100 \%, \mathrm{~B} 2=77 \%, \mathrm{G} 1=$ $64 \%$, and $\mathrm{G} 2=25 \%$. The lower and upper limits of quantification of the kit were 1 and $20 \mathrm{ppb}(\mu \mathrm{g} / \mathrm{kg})$, respectively, per the supplier's information. Samples with aflatoxin levels above the upper quantification limit were diluted and retested.

Fumonisin was extracted from 10-g subsamples of maize flour using $90 \%$ methanol and analyzed with a commercially available ELISA kit per the manufacturer's protocol (Helica Biosystems, Inc.). The solid-phase direct competitive fumonisin ELISA kit (catalog number 951FUM01C-96; Helica Biosystems, Inc.) consisted of a 96-well microplate coated with an antibody that was optimized to cross-react with three fumonisin subtypes (B1, B2, and B3). The lower and upper limits of quantification of the kit were 0.1 and $6 \mathrm{ppm}$, respectively, according to the manufacturer. Samples with toxin values below the limit of quantification were recorded as containing no detectable toxin.

Optical densities of the reactions for both mycotoxins were quantified using a microplate reader (BioTek Instruments, Inc.) with an absorbance filter of $450 \mathrm{~nm}$. Test values were interpreted with reference to standards that were included in each experiment.

Statistical analysis. Statistical analysis was done in JMP Pro (ver. 10; SAS Institute Inc.). For the regional study, correlations were computed between publicly available rainfall estimates, based on satellite imaging and global telecommunication system (Xie and Arkin 1997), and the percentages of samples with detectable aflatoxin $(>1 \mathrm{ppb})$ or with aflatoxin above the regulatory limit $(>10 \mathrm{ppb})$ across the geoclimatic locations. Factors potentially associated with aflatoxin contamination were analyzed using samples only from the Nyanza region; aflatoxin data from the other regions were too skewed to permit a similar analysis (see Results). Aflatoxin data were transformed to logarithm $(\mathrm{ppb}+1)$ and analyzed as a dependent variable in a model in which the 26 factors included in the survey questionnaire served as independent variables. County and village nested in a county were modeled as random effects. Results of the analysis were presented as geometric means that were derived by back-transformation of the least squares means of the transformed aflatoxin data.

For the Bungoma survey, the means, variances and percentages of samples with contamination at different levels were computed for whole grain collected at farmers' storage sheds and for flour collected at the mills. Mycotoxin data of the whole grain collected from the storage sheds was analyzed separately from data of flour samples from the mills; these data were not considered to be directly comparable because of the differences in sampling methods.

To assess the factors associated with the presence or absence of mycotoxins in the Bungoma study, a nominal logistic regression analysis was used on binary-coded mycotoxin data. Samples with detectable toxin (aflatoxin $\geq 1 \mathrm{ppb}$ and fumonisin $\geq 0.1 \mathrm{ppm}$ ) were considered positives and coded 1 , while those with lower values 
were considered as negatives and coded 0 . The questionnaire-based variables used in the regression analysis were sequentially dropped from the logistic model until the best model, based on Akaike's Information Criterion, was obtained.

Pairwise comparisons between mycotoxin levels and covariates were performed using $t$ tests and correlations. Spearman's rank correlation was used for comparisons that involved small sample sizes and for data for which the type and distribution did not meet the assumptions for Pearson's correlation. Paired $t$ tests were used to compare mycotoxin levels in maize that was either treated or nontreated with preservatives. A $\chi^{2}$ test was performed for the differences in weevil infestation between preservative-treated or
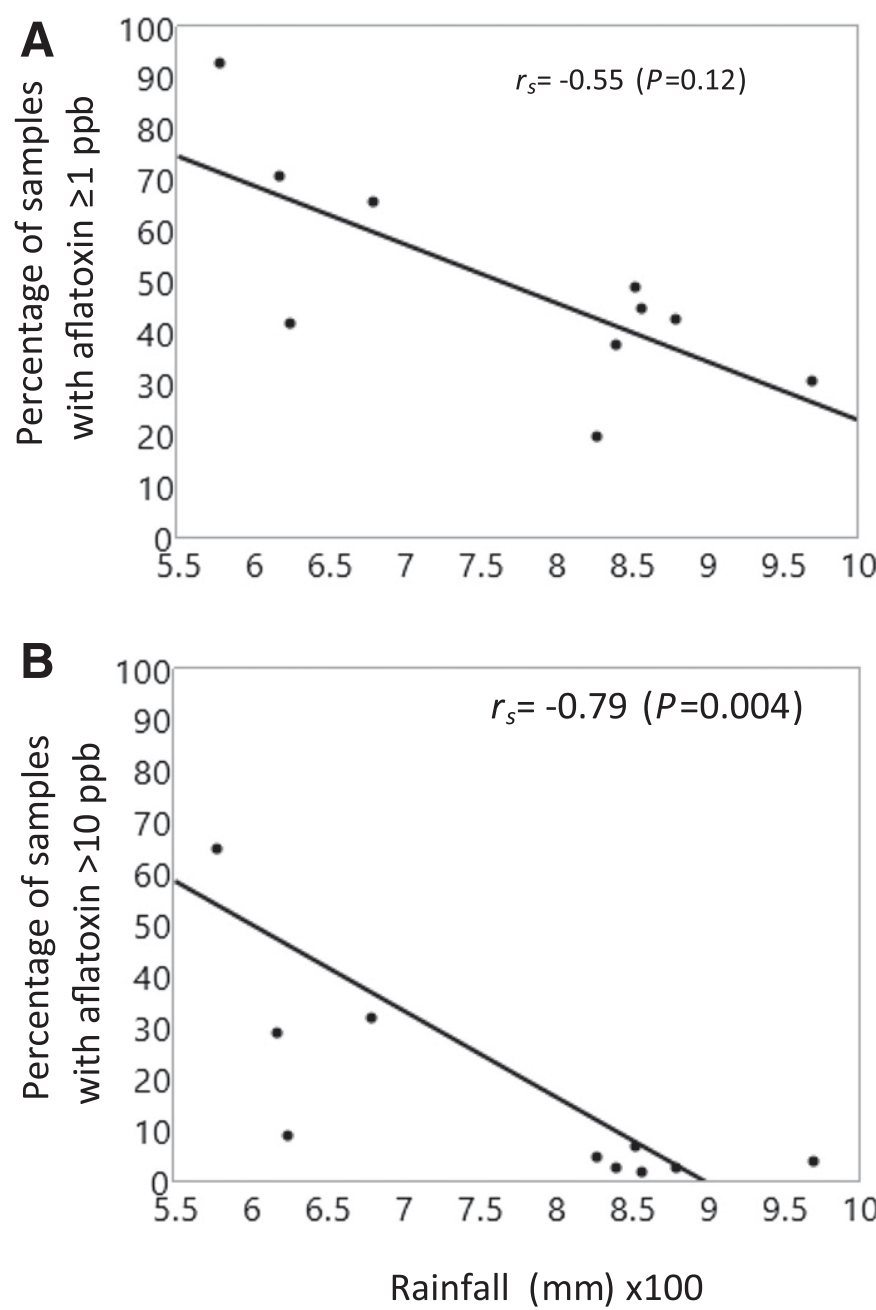

Fig. 2. Correlations between amount of rainfall $(\mathrm{mm})$ and percentages of maize samples with $\mathbf{A}$, detectable aflatoxin $(\geq 1 \mathrm{ppb})$ and $\mathbf{B}$, aflatoxin contamination above the regulatory limit $(10 \mathrm{ppb})$. Samples were from a regional survey of maize at local mills in 2009 in 11 locations in western Kenya. Rainfall data were retrieved from the World Climate repository (http://www. worldclim.org). nontreated maize, differences in the percentages of samples with weevil infestation and mycotoxin contamination among sampling periods, and differences in weevil and mycotoxin contamination among maize varieties.

\section{RESULTS}

Aflatoxin prevalence in regional survey of western Kenya, 2009. Among the 985 maize samples collected from local posho mills in 11 geoclimatic locations, $49 \%$ had detectable levels of aflatoxin and $15 \%$ were contaminated above the regulatory limit (>10 ppb) (Table 2). A descriptive summary of maize acquisition and the corresponding percentage of samples with aflatoxin contamination at different levels is shown in Table 3. The highest percentage of aflatoxin-contaminated maize was observed in two drought-prone subcounties of Homa Bay County (Homa Bay, 66\% and Rachuonyo, 93\%) in the Nyanza region (Tables 1 and 2). Similarly, the Nyanza region had a higher percentage ( 8 to $65 \%$ ) of samples with aflatoxin contamination above the regulatory limit than samples from the Rift Valley and Western regions (2 to 7\%) (Table 2). Aflatoxin levels were significantly associated with AEZ $(P=0.038)$. Mean aflatoxin contamination increased as moisture decreased across the AEZs (geometric mean \pm standard deviation) as follows: humid $(1 \pm 0.3 \mathrm{ppb})$, subhumid $(2.4 \pm 0.4 \mathrm{ppb})$, and semihumid $(9.2 \pm 0.4 \mathrm{ppb})$. Mean contamination differed between humid and semihumid zones $(P<0.05)$. Similarly, the amount of rainfall during the growing season of the sampled maize was negatively correlated with the percentage of samples with aflatoxin above the regulatory limit $\left(r_{s}=-0.79, P=0.004\right)$ (Fig. 2).

Because of relatively low aflatoxin contamination found in the Rift Valley and Western regions (Table 2), the association between aflatoxin and the questionnaire variables was analyzed using data only for the samples from the Nyanza region $(n=118)$. In Nyanza, aflatoxin contamination was associated with the manner in which individuals obtained the maize $(P=0.016)$. Home-grown maize had significantly $(P=0.016)$ less contamination $(2.4 \pm 0.3 \mathrm{ppb} ; n=56)$ than purchased maize $(4.6 \pm 0.3 \mathrm{ppb} ; n=62)$. Among the homegrown samples, aflatoxin contamination was three times greater $(P=0.023)$ in maize grown in monoculture $(4.8 \pm 0.5 \mathrm{ppb} ; n=8)$ than in intercropping $(1.6 \pm 0.3 \mathrm{ppb} ; n=44)$.

Mycotoxin accumulation in selected varieties in storage. We focused our detailed study on the four most popular varieties (H614, H513, WH505, and Local 8) found in 13 villages in Bungoma. These four were cultivated by $47 \%(n=122)$ of the respondent farmers; another 20 minor varieties were also grown in the region. A preharvest survey of 186 farmers in seven villages revealed the following varietal cultivation percentages: H614 (44\%), H513 (36\%), WH505 (13\%), and Local 8 (7\%). Some farmers grew more than one maize variety: 26 farmers (14\%) grew two varieties and 2 farmers (1\%) grew three varieties (Table 4). Factors associated with farmers' varietal choices included seed availability, drought tolerance, earliness of maturity, grain yield, and flour quality (Table 4).

Among samples of the four maize varieties that were collected over three sampling periods $(n=488)$, only $4 \%$ of the samples had detectable aflatoxin (Fig. 3A), with an overall mean of $2.3( \pm 17.1) \mathrm{ppb}$.

TABLE 3. Aflatoxin contamination as a function of maize source in a regional survey of local mills in western Kenya in 2009 a

\begin{tabular}{|c|c|c|c|c|c|c|}
\hline \multirow[b]{2}{*}{ Maize source } & \multicolumn{2}{|c|}{ Samples from each source } & \multicolumn{2}{|c|}{ Samples with detectable aflatoxin $(\geq 1 \mathrm{ppb})^{\mathrm{b}}$} & \multicolumn{2}{|c|}{ Samples with aflatoxin above the regulatory limit $(\geq 10 \mathrm{ppb})$} \\
\hline & $n$ & $\%$ & $n$ & $\%$ & $n$ & $\%$ \\
\hline Local market & 396 & 61 & 158 & 41 & 40 & 10 \\
\hline Home-grown & 210 & 32 & 101 & 48 & 10 & 5 \\
\hline Gifts & 33 & 5 & 17 & 52 & 9 & 27 \\
\hline Food aid & 7 & 1 & 4 & 57 & 1 & 14 \\
\hline
\end{tabular}

a The regulatory limit for aflatoxin in Kenya is $10 \mathrm{ppb}(\mu \mathrm{g} / \mathrm{kg})$.

b Includes samples with aflatoxin above the regulatory limit. 
The likelihood of aflatoxin contamination differed significantly $(P=$ 0.004) among varieties (Table 5). Local 8 and WH505 accounted for $19 \%$ of the samples and did not have detectable aflatoxin. In contrast, aflatoxin was detected in almost $10 \%$ of the samples of both $\mathrm{H} 614$ and $\mathrm{H} 513$, and exceeded $10 \mathrm{ppb}$ in $7 \%$ of samples of H614 and 2\% of H513

TABLE 4. Varietal types, kernel texture, and reasons for farmers' preference of the four popular maize varieties in Bungoma County, western Kenya ${ }^{\mathrm{a}}$

\begin{tabular}{lcccc}
\hline & \multicolumn{4}{c}{ Maize variety } \\
\cline { 2 - 5 } Factor & H614 & H513 & WH505 & LOCAL 8 \\
\hline Varietal type & Hybrid & Hybrid & Hybrid & Open pollinated \\
Kernel type & Flint & Semi- & Dent & Dent \\
& & Flint & & \\
Number of farmers $(n)$ & 93 & 77 & 28 & 14 \\
Percentage of farmers $(\%)$ & 44 & 36 & 13 & 7 \\
Farmers in a category (\%) & & & & \\
Seed obtained by & & & 13 & 6 \\
$\quad$ Bought & 42 & 35 & 13 & 67 \\
$\quad$ Saved & 0 & 11 & 22 & 27 \\
$\quad$ Other & 58 & 54 & 65 & 7 \\
Reason for preference & & & & 7 \\
$\quad$ Cost of seed & 2 & 9 & 19 & 21 \\
$\quad$ Seed availability & 39 & 14 & 5 & 21 \\
$\quad$ Drought tolerance & 0 & 11 & 10 & 14 \\
$\quad$ Earliness & 2 & 0 & 0 & 7 \\
$\quad$ Yield & 47 & 32 & 38 & 21 \\
$\quad$ Pest tolerance & 10 & 7 & 5 & \\
$\quad$ Flour quality & 0 & 25 & 24 &
\end{tabular}

a Data are based on a preharvest survey that was conducted between July and August 2009, with randomly selected farmers $(n=186)$ in seven villages in a humid agroecological zone.

b This category includes farmers that did not disclose the source, missing data, or additional sources (e.g., barter or other trade).
(Fig. 4A). The likelihood of aflatoxin contamination did not differ between $\mathrm{H} 614$ and $\mathrm{H} 513$ (odds ratio $[\mathrm{OR}]=0.774, P=0.514$ ), or among sampling periods (Table 5).

Fumonisin was analyzed in $233(48 \%)$ of the 488 samples and detected in $41 \%$ of them (Fig. 3B). Across the maize varieties, the percentages of samples with detectable fumonisin ranged from 25 to $54 \%$ (Fig. 4B), with an overall mean of $0.533( \pm 1.055) \mathrm{ppm}$. Percentages of samples with fumonisin at $\geq 1 \mathrm{ppm}$ ranged from 11 to $31 \%$ among varieties, and the likelihood of fumonisin contamination differed significantly $(P=0.005)$ among them (Table 5). The likelihood of fumonisin contamination was higher in H614 than in H513 (OR $=0.27, P=0.001)$ and WH505 $(\mathrm{OR}=0.34, P=0.012)$. The likelihood of fumonisin contamination did not differ significantly $(P>0.05)$ among the rest of the varieties or among sampling periods (Table 5).

Grain moisture was significantly higher after harvest $(12.8 \%)$ than in subsequent sampling periods (11.4 and $11.3 \%$ at 2 and 4 months after harvest, respectively; $P<0.0001)$. However, mycotoxin contamination was not correlated with grain moisture $(P>0.05)$, and there were no significant differences in grain moisture among varieties during storage $(P=0.119)$.

Interestingly, mycotoxin levels were not correlated with weevil incidence or ear rot $(P>0.05)$. No weevils were found immediately after harvest but over $20 \%$ of the samples were infested after 2 and 4 months of storage (Fig. 5A). Weevil infestation was not different between 2 and 4 months of storage $\left(\chi^{2}=2.602, P=0.271, n=196\right.$, $d f=2)$. However, the varieties differed significantly $\left(\chi^{2}=19.5, P=\right.$ $0.0005, n=196, d f=4)$. Local 8 was not infested, whereas the other three varieties had varying levels of infestation (Fig. 5B). The percentage of preservative-treated samples $(22 \%)$ that was infested by weevils was not different from that of untreated maize $(24 \%)$ $\left(\chi^{2}=0.056, P=0.972, n=196, d f=2\right)$.
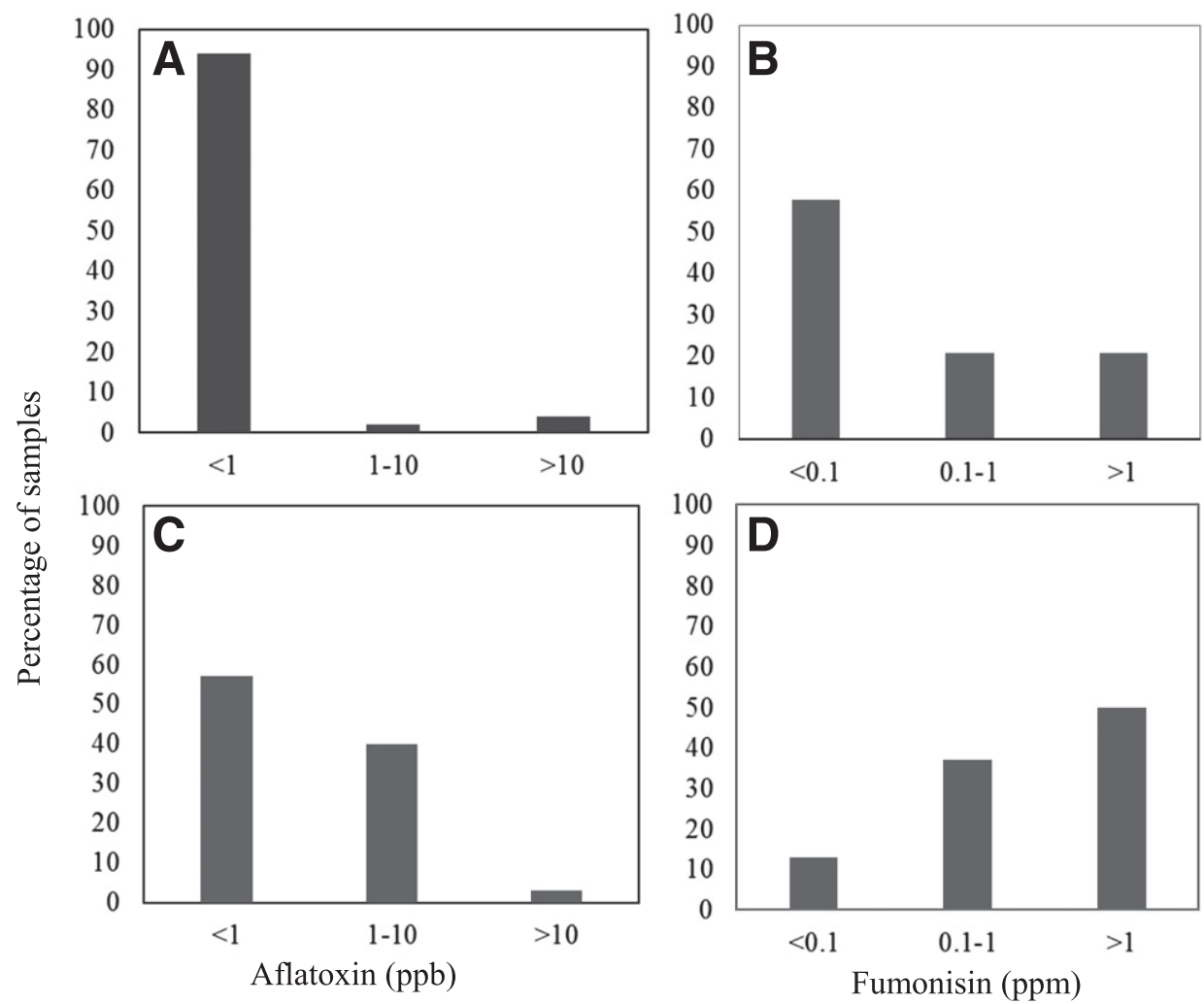

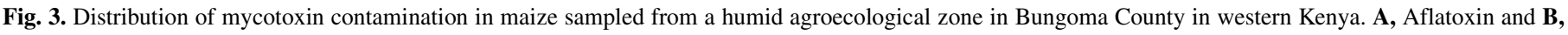

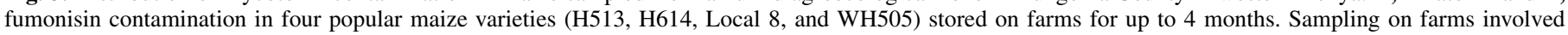

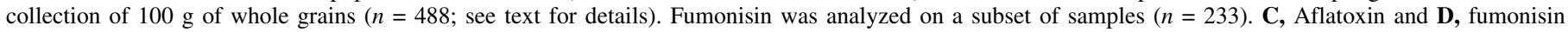

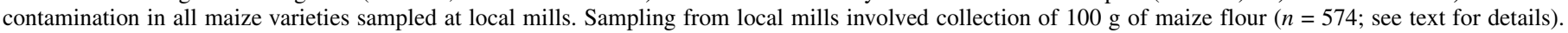

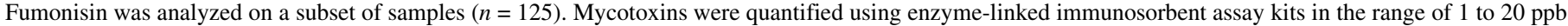
$(\mu \mathrm{g} / \mathrm{kg})$ for aflatoxin and 0.1 to $6 \mathrm{ppm}(\mathrm{mg} / \mathrm{kg})$ for fumonisin. Kenyan regulatory limits are $10 \mathrm{ppb}$ for aflatoxin and $1 \mathrm{ppm}$ for fumonisin. 
Although we found no differences in levels of weevil infestation, the percentage of samples with detectable fumonisin was lower $(P=$ $0.046, n=84)$ when farmers applied preservatives $(24 \%)$ compared with maize stored without preservatives (44\%). In contrast, the percentage of samples with aflatoxin contamination was not

TABLE 5. Effect of four variables on the presence or absence of aflatoxin and fumonisin in popular maize varieties stored for up to 4 months (between 2009 and 2010) in the detailed survey of farms in Bungoma County, western Kenya ${ }^{a}$

\begin{tabular}{lcccccc}
\hline & & \multicolumn{2}{c}{ Aflatoxin $^{\mathrm{b}}$} & & \multicolumn{2}{c}{ Fumonisin $^{\mathrm{c}}$} \\
\cline { 3 - 4 } \cline { 6 - 7 } Source & $d f$ & $\mathrm{~L}-\mathrm{R} \chi^{2}$ & $P$ value & & L-R $\chi^{2}$ & $P$ value \\
\hline Sampling period & 2 & 3.97 & 0.138 & & 3.57 & 0.167 \\
Variety & 3 & 13.31 & 0.004 & & 12.72 & 0.005 \\
Village & 6 & 11.47 & 0.075 & & 3.02 & 0.806 \\
Preservative & 1 & $0.15^{\mathrm{d}}$ & 0.697 & & $3.69^{\mathrm{e}}$ & 0.055 \\
\hline
\end{tabular}

a Mycotoxins were assessed from 100-g whole-grain samples. Likelihood ratio $(\mathrm{L}-\mathrm{R}) \chi^{2}$ tests were based on a nominal logistic regression. Mycotoxin detection limits were $1 \mathrm{ppb}(\mu \mathrm{g} / \mathrm{kg})$ for aflatoxin and $0.1 \mathrm{ppm}(\mathrm{mg} / \mathrm{kg})$ for fumonisin.

b Based on a sample size of $n=488$.

c Subset of samples analyzed for aflatoxin was analyzed for fumonisin $(n=233)$.

${ }^{\mathrm{d}}$ Based on a subset of samples $(n=119)$ that were included in the grain preservative experiment.

e Based on a subset of samples $(n=84)$ that were included in the grain preservative experiment. different with $(10 \%)$ or without $(12 \%)$ preservatives $(P=0.77$, $n=119)$. Moreover, aflatoxin and fumonisin levels were uncorrelated $(r=-0.004)$.

Bungoma survey at local mills. For the Bungoma survey, flour samples collected at local mills were from maize that was either home grown $(57 \%)$ or purchased $(43 \%)$. The percentage of samples that represented purchased maize was lowest at harvest time and increased over time (36, 42, and 51\% at harvest and 2 and 4 months after harvest, respectively). Of the 574 samples collected at the mills, $41 \%$ had detectable aflatoxin, and $4 \%$ exceeded the regulatory limit (Fig. 3C). Overall mean aflatoxin contamination was $2.3( \pm 3.8) \mathrm{ppb}$. Analysis of a subset of the samples for fumonisin $(n=125)$ showed that $87 \%$ had detectable fumonisin and $50 \%$ exceeded the regulatory limit (Fig. 3D). Overall mean fumonisin contamination was $1.9( \pm 3.0) \mathrm{ppm}$.

Approximately a third (31\%) of the 574 samples collected at the mills were reported to be of the four common maize varieties studied in storage. Among these varieties, 30 to $60 \%$ of the samples had detectable levels of aflatoxin contamination (Fig. 4C), with an overall mean of $2.0( \pm 2.88) \mathrm{ppb}$. The percentage of samples of these varieties with detectable aflatoxin did not differ among the sampling times $(P>0.05)$. Only one sample $(1 \%)$ of H614 was above the regulatory limit for aflatoxin; none of the samples of the other three varieties exceeded this limit.

The likelihood of aflatoxin contamination differed significantly $(P=0.0007)$ among sampling times across all varieties. This
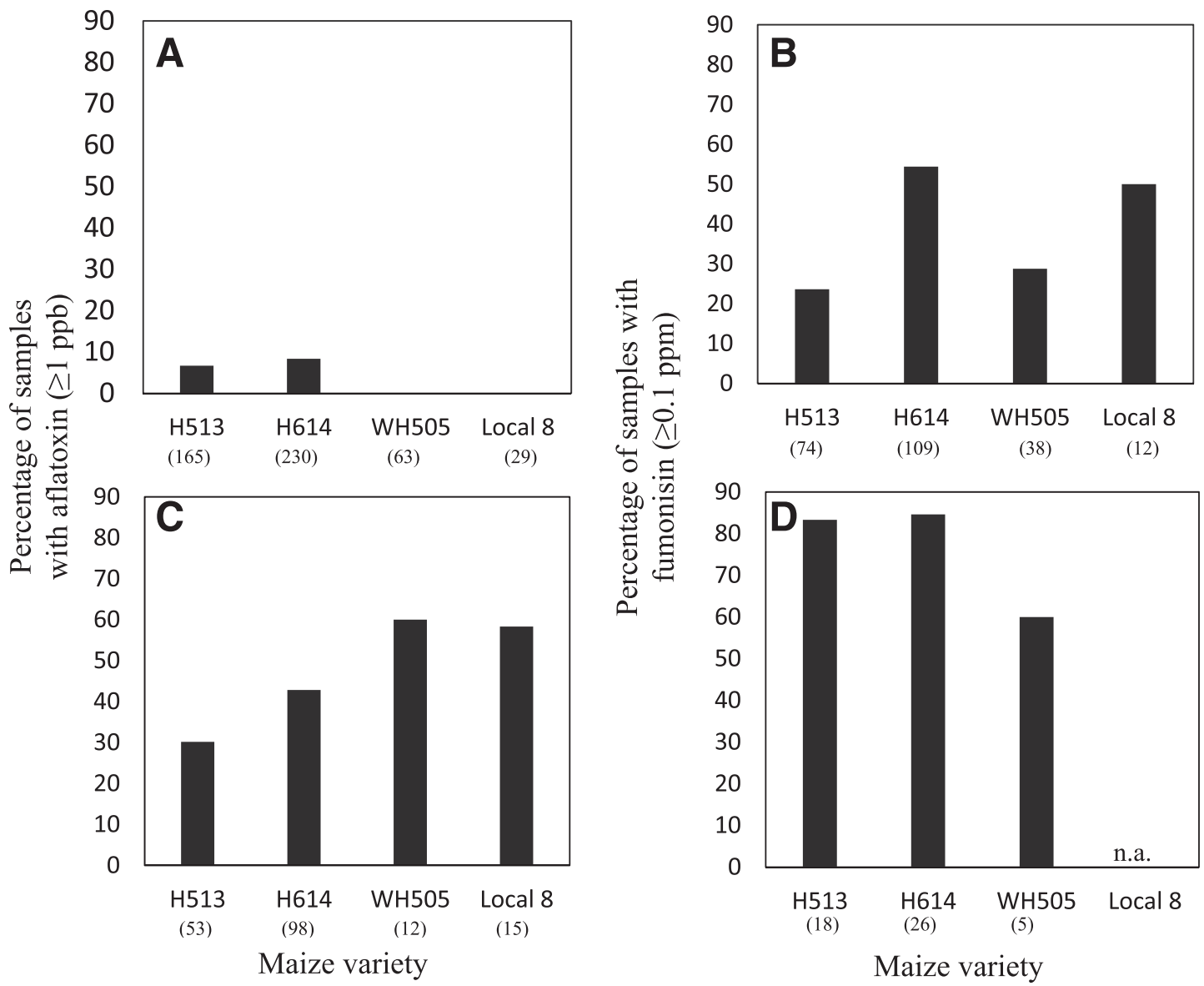

Fig. 4. Distribution of mycotoxin contamination in four popular maize varieties (H513, H614, Local 8, and WH505) sampled from a humid agroecological zone in Bungoma County in western Kenya. A, Aflatoxin and B, fumonisin contamination in maize stored on farms for up to 4 months. Sampling on farms involved collection of $100 \mathrm{~g}$ of whole grains $(n=488$; see text for details). Fumonisin was analyzed on a subset of samples $(n=233$; see text for details). C, Aflatoxin and $\mathbf{D}$, fumonisin contamination in samples from local mills. Sampling from local mills involved collection of $100 \mathrm{~g}$ of maize flour ( $n=574$; see text for details). Fumonisin was analyzed on a subset of samples $(n=125$; see text for details). Mycotoxins were quantified using enzyme-linked immunosorbent assay kits in the range of 1 to $20 \mathrm{ppb}(\mu \mathrm{g} / \mathrm{kg})$ for aflatoxin and 0.1 to $6 \mathrm{ppm}(\mathrm{mg} / \mathrm{kg})$ for fumonisin. Kenyan regulatory limits are $10 \mathrm{ppb}$ for aflatoxin and $1 \mathrm{ppm}$ for fumonisin. Sample sizes are shown in parenthesis below each variety; n.a. = not analyzed. 
likelihood was lowest right after harvest and highest 2 months after harvest. Samples collected 2 months after harvest were 1.6 times more likely to have detectable aflatoxin than those collected right at harvest. The likelihood of aflatoxin contamination at harvest did not differ significantly $(P>0.05)$ with that observed 4 months later. The percentages of samples with aflatoxin contamination above the regulatory limit varied from $2 \%$ right after harvest to 6 and $4 \% 2$ and 4 months later, respectively (Fig. 6A). The percentage of samples with aflatoxin did not differ significantly $(P>0.05)$ between the home-grown and purchased maize at any of the sampling periods (Table 6).

The likelihood of fumonisin contamination differed significantly $(P=0.01)$ among sampling periods. The percentage of samples with detectable fumonisin was $90 \%$ at harvest, $82 \% 2$ months after harvest, and $96 \% 4$ months after harvest. The percentage of samples with fumonisin above the regulatory limit was highest at harvest ( $75 \%$ ), and decreased to $45 \% 2$ months later, followed by a further decrease to $32 \% 4$ months after harvest (Fig. 6B). The percentage of samples with detectable fumonisin did not differ between the purchased and the home-grown maize over the three sampling periods (Table 6).

Mean fumonisin contamination in the four most common maize varieties (H614, H513, WH505, and Local 8), which together were represented by 49 (39\%) of the 125 samples analyzed for fumonisin, was 2.177 ( \pm 3.483$)$ ppm. The percentages of fumonisincontaminated samples from these varieties ranged from 60 to $85 \%$ (Fig. 4D). The percentage of samples with fumonisin contamination above the regulatory limit was $69 \%$ for H614, 50\% for H513, and 20\% for WH505. Samples of Local 8 from the mills were not analyzed for fumonisin, and only five samples were taken from WH505 (Fig. 4D). H614 and H513 did not differ significantly in the likelihood of fumonisin contamination $(P>0.409)$. The likelihood of fumonisin contamination differed among sampling periods and, at harvest, was 22 times greater than in the second sampling period $(\mathrm{OR}=21.5, P=0.02)$. The likelihood of contamination was not significantly different (OR $>999.99, P=$ 0.24 ) between samples collected at harvest and 4 months later but was different between those at harvest and 2 months later (OR > 999.99, $P=0.02$ ).

\section{DISCUSSION}

Outbreaks of fatal aflatoxicosis caused by consumption of aflatoxin-contaminated maize have frequently been reported in eastern Kenya (Azziz-Baumgartner et al. 2005; Daniel et al. 2011; Kang'ethe 2011). It is less clear whether mycotoxins are a chronic or periodic problem in regions of Kenya where fatalities have not been reported. In particular, W. Kenya produces most of the
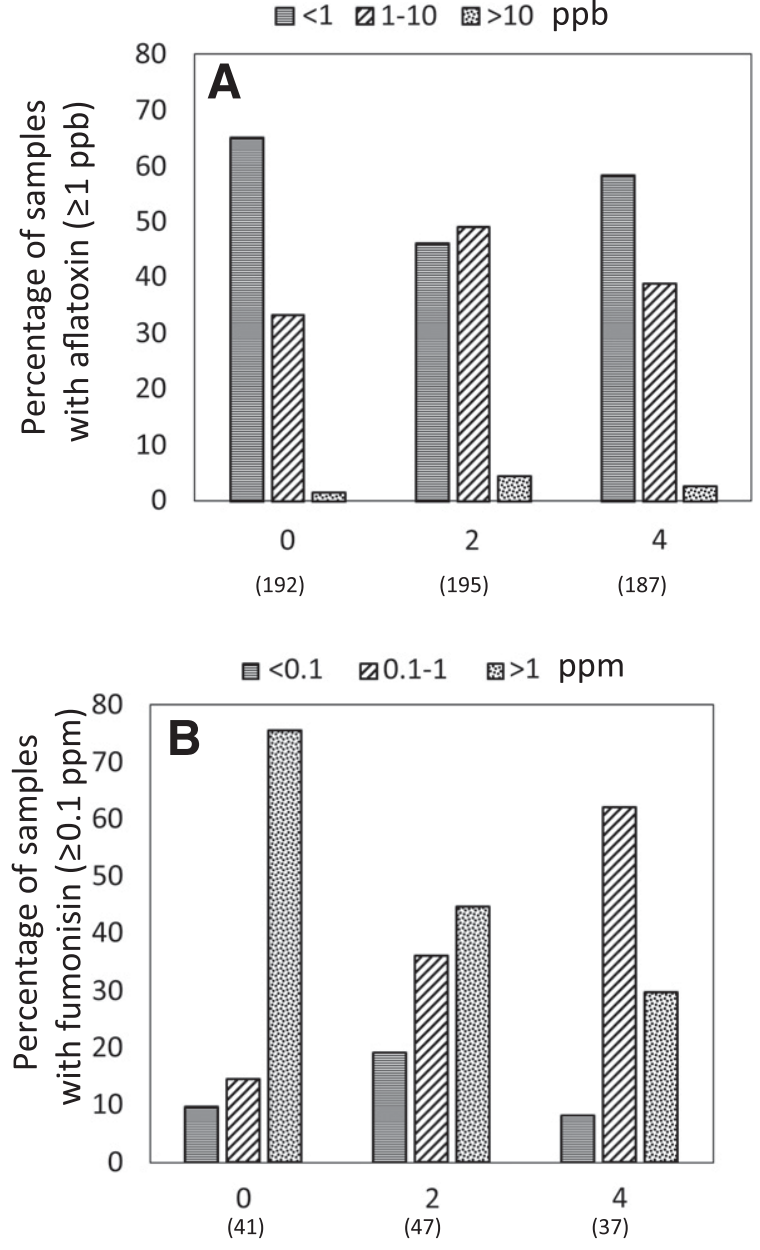

Months after Harvest

Fig. 6. Distribution of mycotoxin contamination in maize sampled from local mills in a humid agroecological zone in Bungoma County in western Kenya. $\mathbf{A}$, Aflatoxin and $\mathbf{B}$, fumonisin contamination up to 4 months after harvest (between 2009 and 2010). Sampling from local mills involved collection of $100 \mathrm{~g}$ of maize flour ( $n=574$; see text for details). Fumonisin was analyzed on a subset of samples $(n=125)$. Sample sizes for each sample time are shown in parentheses below each sampling time. Mycotoxins were quantified using enzyme-linked immunosorbent assay kits in the range of 1 to $20 \mathrm{ppb}(\mu \mathrm{g} / \mathrm{kg})$ for aflatoxin and 0.1 to $6 \mathrm{ppm}(\mathrm{mg} / \mathrm{kg})$ for fumonisin. Kenyan regulatory limits are $10 \mathrm{ppb}$ for aflatoxin and $1 \mathrm{ppm}$ for fumonisin.
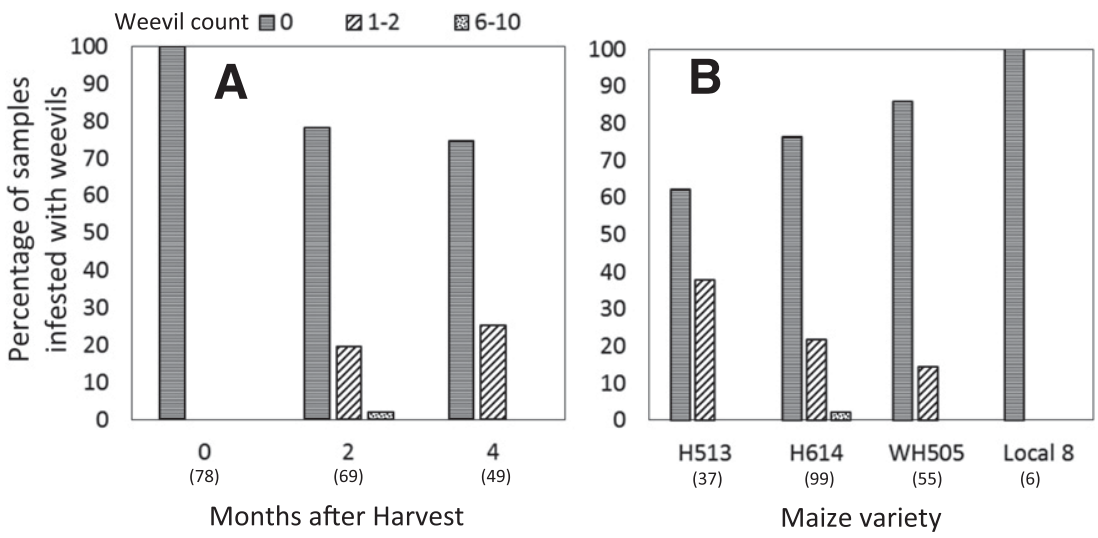

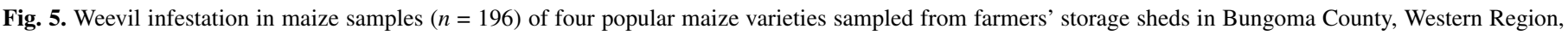

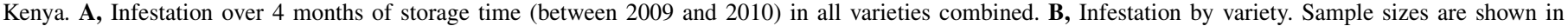
parenthesis below each sampling time and variety. 
country's grain but no comprehensive mycotoxin survey had been conducted to establish the prevalence of aflatoxin or fumonisin contamination in maize. The few published studies on the occurrence of mycotoxins in maize have provided some insight but were based on small geographical areas or small sample sizes or relied on data from one point in the maize value chain (Alakonya et al. 2008b, 2009; Kedera et al. 1999; Mutegi et al. 2009). We extended the understanding through greater sampling efforts across locations and at multiple points along the maize value chain.

We used a regional survey over three AEZs in each of the three regions in the most important maize-producing areas in Kenya to show the prevalence of aflatoxin in maize destined for immediate consumption and its associations with climate (rainfall) and farm management (intercropping versus monoculture). To further investigate the effects of farm management and maize varieties on mycotoxins, we conducted an in-depth survey within one AEZ in one county (a humid AEZ in Bungoma County) to reduce the variation in mycotoxin contamination associated with climate. This latter study provides more information about susceptibility of maize varieties that had previously been investigated (Alakonya et al. 2008a). In addition, this detailed study allowed us to compare aflatoxin and fumonisin contamination in four major varieties at four key points in the maize value chain: at harvest, after 2 and 4 months in storage, and at the mill just prior to consumption. Mycotoxin contamination was also related to storage practices, particularly the use of pesticides and other preservatives.

Although we observed an overall low frequency and level of aflatoxin contamination in western Kenya, we found high levels of contamination associated with certain geoclimatic locations. For instance, the percentages of samples with detectable and above the regulatory limit of aflatoxin observed in the Nyanza region was similar to that reported in regions of eastern Kenya where frequent fatal outbreaks of aflatoxicosis have occurred (Azziz-Baumgartner et al. 2005; Daniel et al. 2011; Mutiga et al. 2014). Despite relatively high aflatoxin contamination in maize in Nyanza, a recent study of aflatoxin in human blood collected from subjects across the country showed that the population of this region had the lowest levels of aflatoxin exposure (Yard et al. 2013). Nonetheless, Yard et al. (2013) found that aflatoxin exposure was widespread across Kenya at a time when no outbreak was recognized, implying that aflatoxin contamination is common in staple foods such as maize but has remained unnoticed because of a lack of surveillance. This discrepancy points to the need for monitoring mycotoxins, even in locations where contamination is not typically high.

We observed a significant association between climatic conditions (rainfall and AEZs) and aflatoxin contamination. Trans Nzoia and Uasin Gishu Counties typically experience more rainfall than the other counties studied, and were found to have less aflatoxin contamination. The highest percentage of samples above the regulatory limit was observed in the drier, semihumid AEZ and the drought-prone regions of Homa Bay County. These findings showed the expected relationship between moisture stress and aflatoxin levels, and are in agreement with the previous reports that aflatoxin contamination is positively correlated with drought (Guo et al. 2008; Kaaya and Kyamuhangire 2006; Kaaya et al. 2006; Magan et al. 2011).

Based on the regional survey, aflatoxin contamination was associated with the manner in which individuals obtained maize. Higher contamination was observed in purchased maize than in home-grown maize. Previous studies have found that Kenyans place higher value on maize they have grown themselves compared with maize that is available for purchase at local markets, perhaps because they expect it to be of higher quality and safety (Hoffmann and Gatobu 2014). In contrast, Daniel et al. (2011) found that AF was higher in home-grown maize than in purchased maize in eastern Kenya. In the current survey, farmers reported that local maize traders cushion themselves against grain losses by blending maize of different qualities. However, because of the recognized lack of correlation between visible moldiness and aflatoxin, it is unclear whether blending might be the cause of differences in contamination observed between marketed and home-grown maize in this study.

Among the home-grown maize samples, intercropped maize had lower aflatoxin contamination than maize that had been grown in monoculture. These findings are consistent with those of the recent survey in eastern Kenya (Mutiga et al. 2014) but contrast with previous reports on the effect of intercropping on aflatoxin levels (Hell 1997; Tedihou et al. 2012). Aflatoxin contamination is positively correlated with crop stress (Chen et al. 2004). Intercropping is intended to increase vegetation diversity and often involves legumes, which can contribute nitrogen to the system. Some crops used in intercropping might reduce plant stress by reducing the rate of evapotranspiration, suppressing weeds, and controlling some diseases (Sun et al. 2006; Unger and Vigil 1998). There is need for experimental studies to establish the specific intercrops and mechanisms through which intercropping reduces aflatoxin contamination.

Except for drought-prone Homa Bay County, the other counties surveyed received relatively high rainfall and had a lower percentage of samples with aflatoxin above the regulatory limit. Most farmers in Bungoma, Trans Nzoia, and Uasin Gishu Counties have larger farms and are likely to have higher income from maize production, as well as better pre- and postharvest management relative to farmers with smaller farms $(<1 \mathrm{ha})$ in the drought-prone areas of the Nyanza region (Nyoro 2002). A recent study in eastern Kenya showed aflatoxin contamination in maize was negatively correlated with farm size and grain yield (Mutiga et al. 2014).

TABLE 6. Sources of maize and percentage of samples with detectable mycotoxins at different sampling periods of the detailed survey of maize flour at local mills in Bungoma County, western Kenya ${ }^{\mathrm{a}}$

\begin{tabular}{|c|c|c|c|c|c|c|}
\hline \multirow[b]{2}{*}{ Mycotoxin at different sampling times } & \multicolumn{2}{|c|}{ Samples with detectable mycotoxin $(\%)$} & \multicolumn{4}{|c|}{ Effect of source of maize } \\
\hline & Home-grown & Purchased & $n$ & $P$ value ${ }^{\mathrm{b}}$ & $\chi^{2}$ & $P$ value $^{\mathrm{c}}$ \\
\hline \multicolumn{7}{|l|}{ Aflatoxin } \\
\hline At harvest & 30 & 43 & 192 & 0.09 & 3.07 & 0.08 \\
\hline 4 months after harvest & 42 & 42 & 187 & 1 & 0.73 & 0.70 \\
\hline \multicolumn{7}{|l|}{ Fumonisin } \\
\hline At harvest & 93 & 85 & 41 & 0.58 & 0.69 & 0.41 \\
\hline
\end{tabular}


We observed greater fumonisin than aflatoxin contamination, as determined by percentages of samples with detectable mycotoxins and above regulatory limits. Contamination by the two mycotoxins was not correlated. The greater extent of fumonisin contamination is in agreement with previous studies (Alakonya et al. 2009; Kedera et al. 1999). The observed high percentage (50\%) of samples with fumonisin above the regulatory limit strongly suggests exposure to unacceptable levels and should prompt investigations into the health implications of fumonisin in the region. Recent studies reported an increase in esophageal cancer in western Kenya, a disease that has been correlated with consumption of fumonisincontaminated foods (Parker et al. 2010; Wakhisi et al. 2005). According to recent global statistics on age-standardized cancer death rates, Kenya was ranked 8th for esophageal cancer and 76th for liver cancer (Chai and Jamal 2012; LeDuc Media 2014). Previous animal coexposure studies have shown that a combined ingestion of aflatoxin and fumonisin can increase the risk of liver cancer compared with aflatoxin alone (Carlson et al. 2001; Gelderblom et al. 2002). Co-occurrence of these mycotoxins could also lead to increased human morbidity and stunted growth in children (Smith et al. 2012; Williams et al. 2004).

Mycotoxin contamination in farmers' storage sheds and at mills was quite different, and must be interpreted in light of the different sampling strategies at these sites. The samples collected at the mills were from larger grain samples ( 2 to $10 \mathrm{~kg}$ ) that were homogenized by milling prior to sampling $100 \mathrm{~g}$ of flour, whereas those collected from storage were 100-g subsamples from less than $1 \mathrm{~kg}$ of whole grain. The percentage of samples with detectable mycotoxin was greater at the mills compared with the storage sheds, most likely because of this discrepancy in sampling. The distribution of mycotoxins is known to be highly skewed among grains, especially for aflatoxin (Schuller et al. 1976; Whitaker 2006; Whitaker et al. 1998). Similar mean aflatoxin contamination for storage and mills implies that contamination was not different between the two sites. However, the higher variances observed in storage compared with the mills for both mycotoxins are consistent with expectations based on the sampling design. Data from the mills were used to give insights on mycotoxin contamination in maize that was being consumed at the time of the survey and, therefore, may be more relevant for understanding human exposure to mycotoxins.

To prevent storage losses, Kenyan farmers apply different types of preservatives to maize before storage. The preservatives used include botanicals (locally known plant derivatives), synthetic pesticides, and ash. Application of preservatives was associated with a decrease in fumonisin contamination but did not affect weevil incidence. Weevils were not correlated with mycotoxin contamination even though they have been correlated previously in other tropical regions. For example, Kaaya et al. (2006) observed a significant association between aflatoxin and weevil damage in stored maize in Uganda. Similarly, Ono et al. (2002) observed a positive correlation between fumonisin and weevil damage. The lack of correlation between fumonisin and weevil incidence in the current study suggests the possibility that the preservatives had a direct effect on $F$. verticillioides in reducing fumonisin; further experimental evidence will be needed to test this hypothesis. Experiments should also focus on how specific preservatives applied by these farmers differ in reducing fumonisin.

We did not detect accumulation of aflatoxin and fumonisin contamination over time during storage. Although reports of increases in fumonisin contamination during storage are inconsistent (Atukwase et al. 2012; Bacon and Nelson 1993; Ono et al. 2002), several studies have reported increases in aflatoxin in stored maize, especially in the tropics (Hell 1997; Kankolongo et al. 2009; Tedihou et al. 2012). In a 12-month experiment in which two groups of maize samples were predried to 11 and $14 \%$ and monitored for fungal colonization and fumonisin, no significant increases in fumonisin were reported (Ono et al. 2002). This finding was attributed to low water activity that might have inhibited growth of fumonisin-producing fungi. In the current study, grain moisture during storage ranged from 11.3 to $12.8 \%$ and was below the maximum $13 \%$ that is recommended for grain storage in the tropics, and was below $15 \%$, which is favorable for growth and toxin production by A. flavus and F. verticillioides (Kaaya et al. 2005; Proctor 1994). Low grain moisture and low weevil incidence during storage suggest that maize was stored under conditions that were not optimal for additional aflatoxin and fumonisin accumulation. Although variation in toxigenicity of fungal populations could affect the frequency and amount of mycotoxins (Payne and Yu 2010; Probst et al. 2012), we did not determine the toxigenicity of fungal populations in the current study.

The percentage of aflatoxin-contaminated samples was highest in flour samples that were collected 2 months after harvest, while the percentage of samples with fumonisin above the regulatory limit was highest at harvest and decreased over time. Because the observed trends were maintained even when only home-grown maize samples were considered, we speculate that they may have been related to grain sorting. A survey conducted in eastern Kenya revealed greater reduction of fumonisin than aflatoxin when consumers sorted their maize prior to milling (Mutiga et al. 2014). A low correlation between apparent moldiness and aflatoxin contamination has been reported previously, and visual sorting of maize was not as efficient in reducing aflatoxin as it was with fumonisin (Fandohan et al. 2005; van der Westhuizen et al. 2011).

We observed differences in mycotoxin contamination among the four most common maize varieties. H614 and H513 showed consistent contamination by both aflatoxin and fumonisin in storage and at mills. Local 8 and WH505 were contaminated by fumonisin but not aflatoxin at the storage sheds, whereas both toxins were detected on these varieties in samples from the mills. H614 and H513 were the most popular among the farmers because of high grain yield but these varieties were vulnerable to weevil damage and mycotoxin accumulation. The observed vulnerability of the two most popular varieties implies that mycotoxin and insect resistance traits were not adequately considered during breeding for increased grain yield.

Previous work showed that flint maize genotypes were more resistant to preharvest aflatoxin accumulation than dent genotypes (Betran et al. 2006). If texture (endosperm type) had a major effect on mycotoxin accumulation, H614 would have been the most resistant variety, but it was the most contaminated of the varieties we investigated. Insect damage has previously been associated with mycotoxin contamination (Hell et al. 2000; Wu 2007). However, we did not find a correlation between mycotoxins and weevils. The observation that the four most popular varieties were highly contaminated with fumonisin in storage and at the mills implies that fumonisin is a health threat to maize consumers. The findings that Local 8 and WH505 did not have detectable aflatoxin in storage would have led us to conclude that they were resistant; however, the complementary findings at the mills showed otherwise. There is need for breeding efforts to combine mycotoxin and insect resistances in local varieties.

In conclusion, the regional survey of maize at local mills showed that aflatoxin is a significant contaminant in a wide geographical area of Kenya's most important maize-producing region. Aflatoxin contamination was associated with drought and cropping systems in a manner consistent with previous findings. The detailed parallel studies conducted at storage sheds and local mills confirmed the previously reported higher prevalence of fumonisin than aflatoxin in this part of Kenya, and gave insights on varietal differences in mycotoxin contamination in storage. Local mills are potentially important venues for mycotoxin mitigation approaches. Such approaches might include surveillance, education programs to create awareness, introduction of mycotoxin-binding agents (Brown et al. 2014; Wang et al. 2008), and grain sorting (Pearson et al. 2004). Mycotoxin surveillance and mycotoxin-related work 
should include all maize-producing regions of Kenya and other similar tropical agroclimatic locations, and not only areas with acute outbreaks of mycotoxicosis.

\section{ACKNOWLEDGMENTS}

We thank the Kenyan authorities for permission and guidance for the recruitment of the study participants, the research assistants who contributed to different stages of this work, R. Darnell (Commonwealth Scientific and Industrial Research Organization, CSIRO, Australia) and F. Vermeylen (Cornell University's Statistical Consulting Unit) for providing statistical advice, and K. Jenkins (Cornell University's Mann Library Geospatial Applications Unit) for providing geographical information systems technical advice. This work was supported by the Atkinson Center for Sustainable Future (ACSF) at Cornell University; Cornell International Institute for Food, Agriculture and Development (CIIFAD) through its Stimulating Agricultural and Rural Transformation (StART) initiative; and The McKnight Foundation. Finally, we acknowledge the price discounts on mycotoxin analysis kits from Helica Biosystems, Inc., which allowed analysis of greater sample sizes than would otherwise have been feasible.

\section{LITERATURE CITED}

Ahmed, M. 2011. Product selection for price incentives and disincentives calculations in Kenya. FAO. Online publication. http://www.fao.org/

Alakonya, A. E., Monda, E. O., and Ajanga, S. 2008a. Effect of delayed harvesting on maize ear rot in western Kenya. Am. Eurasian J. Agric. Environ. Sci. 4:372-380.

Alakonya, A. E., Monda, E. O., and Ajanga, S. 2008b. Management of Fusarium verticillioides root infection court in maize using organic soil amendments. World Appl. Sci. J. 5:161-170.

Alakonya, A. E., Monda, E. O., and Ajanga, S. 2009. Fumonisin B(1) and aflatoxin B(1) levels in Kenyan maize. J. Plant Pathol. 91:459-464.

Atukwase, A., Kaaya, A. N., and Muyanja, C. 2009. Factors associated with fumonisin contamination of maize in Uganda. J. Sci. Food Agric. 89: 2393-2398.

Atukwase, A., Kaaya, A. N., and Muyanja, C. 2012. Dynamics of Fusarium and fumonisins in maize during storage A case of the traditional storage structures commonly used in Uganda. Food Control 26:200-205.

Azziz-Baumgartner, E., Lindblade, K., Gieseker, K., Rogers, H. S., Kieszak, S., Njapau, H., Schleicher, R., McCoy, L. F., Misore, A., DeCock, K., Rubin, C., and Slutsker, L. 2005. Case-control study of an acute aflatoxicosis outbreak, Kenya, 2004. Environ. Health Perspect. 113:1779-1783.

Bacon, C. W., and Nelson, P. E. 1993. Fumonisin production by toxigenic strains of Fusarium moniliforme and Fusarium proliferatum in corn. J. Food Prot. 6: 460-546.

Betran, F. J., Bhatnagar, S., Isakeit, T., Odvody, G., and Mayfield, K. 2006. Aflatoxin accumulation and associated traits in QPM maize inbreds and their testcrosses. Euphytica 152:247-257.

Bolduan, C., Miedaner, T., Schipprack, W., Dhillon, B. S., and Melchinger, A. E. 2009. Genetic variation for resistance to ear rots and mycotoxins contamination in early European maize inbred lines. Crop Sci. 49:2019-2028.

Brown, K. A., Mays, T., Romoser, A., Marroquin-Cardona, A., Mitchell, N. J., Elmore, S. E., and Phillips, T. D. 2014. Modified hydra bioassay to evaluate the toxicity of multiple mycotoxins and predict the detoxification efficacy of a clay-based sorbent. J. Appl. Toxicol. 34:40-48.

Bruns, H. A. 2003. Controlling aflatoxin and fumonisin in maize by crop management. J. Toxicol. Toxin Rev. 22:153-173.

Burger, H. M., Lombard, M. J., Shephard, G. S., Rheeder, J. R., van der Westhuizen, L., and Gelderblom, W. C. A. 2010. Dietary fumonisin exposure in a rural population of South Africa. Food Chem. Toxicol. 48: 2103-2108.

Carlson, D. B., Williams, D. E., Spitsbergen, J. M., Ross, P. F., Bacon, C. W., Meredith, F. I., and Riley, R. T. 2001. Fumonisin B-1 promotes aflatoxin $\mathrm{B}-1$ and $\mathrm{N}$-methyl- $\mathrm{N}^{\prime}$-nitro-nitrosoguanidine-initiated liver tumors in rainbow trout. Toxicol. Appl. Pharmacol. 172:29-36.

Chai, J., and Jamal, M. M. 2012. Esophageal malignancy: A growing concern. World J. Gastroenterol. 18:6521-6526.

Chen, Z. Y., Brown, R. L., and Cleveland, T. E. 2004. Evidence for an association in corn between stress tolerance and resistance to Aspergillus flavus infection and aflatoxin contamination. Afr. J. Biotechnol. 3:693-699.

Clements, M. J., Maragos, C. A., Pataky, J. K., and White, D. G. 2004. Sources of resistance to fumonisin accumulation in grain and Fusarium ear and kernel rot of corn. Phytopathology 94:251-260.

Daniel, J. H., Lewis, L. W., Redwood, Y. A., Kieszak, S., Breiman, R. F., Flanders, W. D., Bell, C., Mwihia, J., Ogana, G., Likimani, S., Straetemans,
M., and McGeehin, M. A. 2011. Comprehensive assessment of maize aflatoxin levels in Eastern Kenya, 2005-2007. Environ. Health Perspect. 119: 1794-1799.

Fandohan, P., Zoumenou, D., Hounhouigan, D. J., Marasas, W. F. O., Wingfield, M. J., and Hell, K. 2005. Fate of aflatoxins and fumonisins during the processing of maize into food products in Benin. Int. J. Food Microbiol. 98:249-259.

Fountain, J. C., Scully, B. T., Ni, X. Z., Kemerait, R. C., Lee, R. D., Chen, Z. Y. and Guo, B. 2014. Environmental influences on maize-Aspergillus flavus interactions and aflatoxin production. Front. Microbiol. 5:40.

Gelderblom, W. C. A., Marasas, W. F. O., Lebepe-Mazur, S., Swanevelder, S., Vessey, C. J., and Hall, P. D. 2002. Interaction of fumonisin B-1 and aflatoxin B-1 in a short-term carcinogenesis model in rat liver. Toxicology 171:161-173.

Guo, B. Z., Chen, Z. Y., Lee, R. D., and Scully, B. T. 2008. Drought stress and preharvest aflatoxin contamination in agricultural commodity: Genetics, genomics and proteomics. J. Integr. Plant Biol. 50:1281-1291.

Hell, K. 1997. Factors contributing to the distribution and incidence of aflatoxin producing fungi in stored maize in Benin. Ph.D. dissertation, University of Hannover.

Hell, K., Cardwell, K. F., Setamou, M., and Schulthess, F. 2000. Influence of insect infestation on aflatoxin contamination of stored maize in four agroecological regions in Benin. Afr. Entomol. 8:169-177.

Hell, K., Fandohan, P., Kiewnick, S., Sikora, R., and Cotty, P. J. 2008. Pre- and postharvest management of aflatoxin in maize: An African perspective. Pages 219-229 in: Mycotoxins: Detection Methods, Management, Public Health and Agricultural Trade. J. F. Leslie, R. Bandyopadhyay, and A. Visconti, eds. CABI, Wallingford, UK.

Hell, K., and Mutegi, C. 2011. Aflatoxin control and prevention strategies in key crops of Sub-Saharan Africa. Afr. J. Microbiol. Res. 5:459-466.

Hoffmann, V., and Gatobu, K. M. 2014. Growing their own: Unobservable quality and the value of self-provisioning. J. Dev. Econ. 106:168-178.

Jaetzold, R., and Schmidt, H. 1982. Farm Management Handbook of Kenya. Part A: West Kenya (Nyanza and Western Provinces). Ministry of Agriculture, Nairobi, Kenya.

Jaetzold, R., Schmidt, H., Hornetz, B., and Shisanya, C. 2006. Part A: West Kenya, Vol. II: Natural Conditions and Farm Management Information. Kenyan Ministry of Agriculture, Nairobi, Kenya.

Kaaya, A. N., and Kyamuhangire, W. 2006. The effect of storage time and agroecological zone on mould incidence and aflatoxin contamination of maize from traders in Uganda. Int. J. Food Microbiol. 110:217-223.

Kaaya, A. N., Kyamuhangire, W., and Kyamanywa, S. 2006. Factors affecting aflatoxin contamination of harvested maize in the three agroecological zones of Uganda. J. Appl. Sci. 6:2401-2407.

Kaaya, A. N., Warren, H. L., Kyamanywa, S., and Kyamuhangire, W. 2005. The effect of delayed harvest on moisture content, insect damage, moulds and aflatoxin contamination of maize in Mayuge district of Uganda. J. Sci. Food Agric. 85:2595-2599.

Kang'ethe, E. 2011. Situation analysis: Improving food safety in the maize value chain in Kenya. Online publication. Food and Agriculture Organization (FAO), Nairobi, Kenya.

Kankolongo, M. A., Hell, K., and Nawa, I. N. 2009. Assessment for fungal, mycotoxin and insect spoilage in maize stored for human consumption in Zambia. J. Sci. Food Agric. 89:1366-1375.

Kedera, C. J., Plattner, R. D., and Desjardins, A. E. 1999. Incidence of Fusarium spp. and levels of fumonisin B-1 in maize in western Kenya. Appl. Environ. Microbiol. 65:41-44.

Kimanya, M. E., De Meulenaer, B., Roberfroid, D., Lachat, C., and Kolsteren, P. 2010. Fumonisin exposure through maize in complementary foods is inversely associated with linear growth of infants in Tanzania. Mol. Nutr. Food Res. 54:1659-1667.

LeDuc Media. 2014. World health rankings: Live longer live better. Online publication. http://www.worldlifeexpectancy.com/world-health-rankings

Magan, N., Medina, A., and Aldred, D. 2011. Possible climate-change effects on mycotoxin contamination of food crops pre- and postharvest. Plant Pathol. 60:150-163.

Mutegi, C. K., Ngugi, H. K., Hendriks, S. L., and Jones, R. B. 2009. Prevalence and factors associated with aflatoxin contamination of peanuts from Western Kenya. Int. J. Food Microbiol. 130:27-34.

Mutiga, S. K., Were, V., Hoffmann, V., Harvey, J. W., Milgroom, M. G., and Nelson, R. J. 2014. Extent and drivers of mycotoxin contamination: Inferences from a survey of Kenyan maize mills. Phytopathology 104: 1221-1231.

Nyikal, J., Misore, A., Nzioka, C., Njuguna, C., Muchiri, E., Njau, J., Maingi, S., Njoroge, J., Mutiso, J., Onteri, J., Langat, A., Kilei, I. K., Nyamongo, J., Ogana, G., Muture, B., Tukei, P., Onyango, C., Ochieng, W., Tetteh, C., Likimani, S., Nguku, P., Galgalo, T., Kibet, S., Manya, A., Dahiye, A., Mwihia, J., Mugoya, I., Onsongo, J., Ngindu, A., DeCock, K. M., Lindblade, K., Slutsker, L., Amornkul, P., Rosen, D., Feiken, D.,Thomas, T., 
Mensah, P., Eseko, N., Nejjar, A., Onsongo, M., Kessel, F., Njapau, H., Park, D. L., Lewis, L., Luber, G., Rogers, H., Backer, L., Rubin, C., Gieseker, K. E., Azziz-Baumgartner, E., Chege, W., and Bowen, A. 2004. Outbreak of aflatoxin poisoning-Eastern and Central Provinces, Kenya. Pages 790-793 in: Morb. Mortal. Wkly. Rep. Center for Disease Control and Prevention (CDC), Atlanta, GA.

Nyoro, J. K. 2002. Kenya's competitiveness in domestic maize production: Implications for food security. Tegemeo Institute, Egerton University, Kenya. Online publication. http://www.ascleiden.n1/Pdf/paper07112002.pdf

Okoth, S., Nyongesa, B., Ayugi, V., Kang'ethe, E., Korhonen, H., and Joutsjoki, V. 2012. Toxigenic potential of Aspergillus species occurring on maize kernels from two agro-ecological zones in Kenya. Toxins 4:991-1007.

Ono, E. Y. S., Sasaki, E. Y., Hashimoto, E. H., Hara, L. N., Correa, B., Itano, E. N., Sugiura, T., Ueno, Y., and Hirooka, E. Y. 2002. Post-harvest storage of corn: Effect of beginning moisture content on mycoflora and fumonisin contamination. Food Addit. Contam. 19:1081-1090.

Parker, R. K., Dawsey, S. M., Abnet, C. C., and White, R. E. 2010. Frequent occurrence of esophageal cancer in young people in western Kenya. Dis. Esophagus 23:128-135.

Payne, G. A., and Yu, J. 2010. Ecology, Development and Gene Regulation in Aspergillus flavus. Caister Academic Press, UK.

Pearson, T. C., Wicklow, D. T., and Pasikatan, M. C. 2004. Reduction of aflatoxin and fumonisin contamination in yellow corn by high-speed dualwavelength sorting. Cereal Chem. 81:490-498.

Probst, C., Callicott, K. A., and Cotty, P. J. 2012. Deadly strains of Kenyan Aspergillus are distinct from other aflatoxin producers. Eur. J. Plant Pathol. 132:419-429.

Proctor, D. L. 1994. Grain storage techniques-Evolution and trends in developing countries. FAO Agric. Serv. Bull. No. 109. Online publication. http://www.fao.org/docrep/T1838E/T1838E00.htm

Reynolds, C. 2009. Kenya's grain basket experiences drought and lowers "long rains" corn output. United States Department of Agriculture-FAS, Office of Global Analysis. Online publication. http://www.pecad.fas.usda.gov/

Schuller, P. L., Horwitz, W., and Stoloff, L. 1976. Review of sampling plans and collaboratively studied methods of analysis for aflatoxins. J. AOAC Int. 59:1315-1343

Smith, L. E., Stoltzfus, R. J., and Prendergast, A. 2012. Food chain mycotoxin exposure, gut health, and impaired growth: A conceptual framework. Adv. Nutr. 3:526-531.

Sun, Y., Zhou, T. F., Wang, Y. Y., Chen, J. B., He, X. H., Li, C. Y., Zhu, Y. Y., Sun, Y., Zhou, T. F., Wang, Y. Y., Chen, J. B., He, X. H., Li, C. Y., and Zhu, Y. Y. 2006. Effect of intercropping on disease management and yield of chilli pepper and maize. Acta Hortic. 33:995-1000.

Tedihou, E., Olatinwo, R., Hell, K., Hau, B., and Hoogenboom, G. 2012. Effects of variety, cropping system and soil inoculation with Aspergillus flavus on aflatoxin levels during storage of maize. Trop. Plant Pathol. 37:25-36.

Tegemeo Institute. 2010. Kenya baseline study. The Alliance for a Green Revolution in Africa (AGRA). Online publication. http://agra-alliance. org/our-results/program-baseline-studies/
Unger, P. W., and Vigil, M. F. 1998. Cover crop effects on soil water relationships. J. Soil Water Conserv. 53:200-207.

van der Westhuizen, L., Shephard, G. S., Rheeder, J. P., Burger, H. M., Gelderblom, W. C. A., Wild, C. P., and Gong, Y. Y. 2011. Optimising sorting and washing of home-grown maize to reduce fumonisin contamination under laboratory-controlled conditions. Food Control 22:396-400.

van Egmond, H. P., Schothorst, R. C., and Jonker, M. A. 2007. Regulations relating to mycotoxins in food. Anal. Bioanal. Chem. 389:147-157.

Wakhisi, J., Patel, K., Buziba, N., and Rotich, J. 2005. Esophageal cancer in north Rift Valley of Western Kenya. Afr. J. Health Sci. 5:157-63.

Wang, P., Afriyie-Gyawu, E., Tang, Y., Johnson, N. M., Xu, L., Tang, L., Huebner, H. J., Ankrah, N. A., Ofori-Adjei, D., Ellis, W., Jolly, P. E., Williams, J. H., Wang, J. S., and Phillips, T. D. 2008. NovaSil clay intervention in Ghanaians at high risk for aflatoxicosis: II. Reduction in biomarkers of aflatoxin exposure in blood and urine. Food Addit. Contam. Part A 25:622-634.

Whitaker, T. B. 2006. Sampling foods for mycotoxins. Food Addit. Contam. 23:50-61.

Whitaker, T. B., ed. 2011. Sampling Procedures to Detect Mycotoxins in Agricultural Commodities. Springer, New York.

Whitaker, T. B., Doko, M. B., Maestroni, B. M., Slate, A. B., and Ogunbanwo, B. F. 2007. Evaluating the performance of sampling plans to detect fumonisin B-1 in maize lots marketed in Nigeria. J. AOAC Int. 90: 1050-1059.

Whitaker, T. B., Trucksess, M. W., Johansson, A. S., Giesbrecht, F. G., Hagler, W. M., and Bowman, D. T. 1998. Variability associated with testing shelled corn for fumonisin. J. AOAC Int. 81:1162-1168.

Wiatrak, P. J., Wright, D. L., Marois, J. J., and Wilson, D. 2005. Influence of planting date on aflatoxin accumulation in $\mathrm{Bt}$, non-Bt, and tropical non-Bt hybrids. Agron. J. 97:440-445.

Williams, J. H., Phillips, T. D., Jolly, P. E., Stiles, J. K., Jolly, C. M., and Aggarwal, D. 2004. Human aflatoxicosis in developing countries: A review of toxicology, exposure, potential health consequences, and interventions. Am. J. Clin. Nutr. 80:1106-1122.

Williams, W. P. 2006. Breeding for resistance to aflatoxin accumulation in maize. Mycotoxin Res. 22:27-32.

Williams, W. P., Windham, G. L., Buckley, P. M., and Perkins, J. M. 2005. Southwestern corn borer damage and aflatoxin accumulation in conventional and transgenic corn hybrids. Field Crops Res. 91:329-336.

Wu, F. 2007. Bt corn and impact on mycotoxins. CAB Rev. Perspect. Agric. Vet. Sci. Nutr. Nat. Resour. 2, No. 060.

Xie, P. P., and Arkin, P. A. 1997. Global precipitation: A 17-year monthly analysis based on gauge observations, satellite estimates, and numerical model outputs. Bull. Am. Meteorol. Soc. 78:2539-2558.

Yard, E. E., Daniel, J. H., Lewis, L. S., Rybak, M. E., Paliakov, E. M., Kim, A. A., Montgomery, J. M., Bunnell, R., Abudo, M. U., Akhwale, W., Breiman, R. F., and Sharif, S. K. 2013. Human aflatoxin exposure in Kenya, 2007: A cross-sectional study. Food Addit. Contam. Part A 30: 1322-1331. 